\title{
The Burden of Chronic Obstructive Lung Disease Disease on the Health System
}

\author{
(1) Kerim Yeșildağ ${ }^{1}$, (1) Önder Aydemir²
}

1Department of Chest Diseases, Konya Numune Hospital, Konya, Turkey

2Department of Public Health, Konya Provincial Health Directorate, Konya, Turkey

\begin{abstract}
Aim: To analyze the cost of patients hospitalized in secondary and tertiary hospitals due to the diagnosis of Chronic Obstructive Lung Disease (COPD) and to draw attention to the cost of COPD and the reasons that increase the cost in our country.

Materials and Methods: This research was carried out in a chest diseases clinic in second and third-level hospitals affiliated with the ministry of health, between 1 January 2018-31 December 2018. Demographic features, smoking, duration of hospitalization, length of hospitalization in intensive care, antibiotics used, number of outpatients applied, total hospitalization cost, total costs and duration of antibiotics used were recorded. Costs were stated in Turkish Lira and converted into dollars. Cost data of patients with more than one hospitalization were entered separately.

Results: The numbers of men and women were equal in both 2nd level and 3rd level patients. Looking at patients with COPD in both the secondary and tertiary, total hospital cost in patients was significantly higher than those who did not. When the length and number of hospitalization increased, the total cost of the hospital increased significantly. Significant differences were not found between age groups, gender, smoking status, comorbidities, antibiotic use, number of outpatient clinic admissions, and the number of hospitalizations in the last two years in terms of total hospital cost.

Conclusion: The elimination and prevention of both internal and external factors that cause the disease, especially without the need for medication, is of great importance in terms of financial and labor loss prevention and reduction.
\end{abstract}

Keywords: Chronic obstructive lung disease, COPD, the burden of COPD, hospital cost, hospital cost in the health system

\section{Introduction}

The Chronic Obstructive Lung Disease (COPD) is defined as a general preventable disease characterized with frequent respiratory symptoms and airflow limitation by The Global Initiative for Chronic Obstructive Lung Disease (GOLD) 2017 (1).

The COPD leads an important challenge for the health care provider and it is the third leading cause of death in the United States in 2014 (2). Also the COPD is the fourth leading cause of death all around the Word (3). Risk factors for the development of COPD include occupational exposures (chemical agents, fumes) and dust, indoor air pollution (Wood burning stove, biomass fuel), asthma and airway hyperresponsiveness $(4,5)$.

Countries use a significant portion of their Gross Domestic Product, and individuals' income, for health expenditures. As a result of this, the cost of healthcare services is one of the important issues that are constantly on the agenda (6). It was announced that the COPD has created a significant financial burden of approximately $\$ 50$ billion in the spending of the US government in 2010 (7).

COPD is a common health problem that causes both labor loss and financial loss. In particular, the increase in the frequency of hospital admissions, the increase in hospitalization and the 
increase in the drugs used create great burdens on the health system of governments. For this reason, it is great importance to take measures for reduction of hospital admissions and management of the disease including non-pharmacological treatment options whenever possible.

In the current study, we aim to analyze the cost of patients hospitalized in 2rd and 3rd hospitals due to the COPD and to draw attention to the cost of COPD that increase the cost in our country.

\section{Materials and Methods}

This research was carried out the chest diseases clinic in second and third level hospitals affiliated to the ministry of health in Konya province, between 1 January 2018 - 31 December 2018. The data of 100 patients (fifty men and fifty women) who were hospitalized and followed up with COPD diagnoses over the years were analyzed.

The study was conducted with the permission and approval of Konya Provincial Health Directorate commission with the following date and numbered (Date: 05/07/2018/ Number:16-03). The patients admitted to the hospital for other reasons than COPD were not included in the current study. For this purpose, approximately ....patients were excluded in the current study. The study was done retrospectively. As the limitations of the study, it can be given that it is conducted only in one center and it covers the last two years.

Demographic data such as age and gender of the patients, smoking, duration of hospitalization, length of hospitalization in intensive care, diseases in addition to COPD, antibiotics used, number of outpatient apply in the last two years, total number of hospitalizations in the last two years, total hospitalization cost, total hospitalization cost of intensive care, daily costs of antibiotics used, total costs of antibiotics used, duration of antibiotics were recorded. Costs were stated in Turkish Lira (TL). It was converted into dollars as a currency using the exchange rate from which the data was taken. Cost data of patients with more than one hospitalization were entered separately.

This study was approved by University of Health Sciences, Konya Training and Research Hospital (decision no and date: 16-03, 05/07/2018).

\section{Statistical Analysis}

The research data were uploaded and analyzed via "SPSS (Statistical Package for Social Sciences) for Windows 22.0 (SPSS Inc, Chicago, IL)". Descriptive statistics were presented as median (interquartile range), frequency distribution and percentage.
Pearson Chi-Square Test and Fisher's Exact Test were used to evaluate categorical variables. The suitability of variables to normal distribution was examined using visual (histogram and probability graphs) and analytical methods (KolmogorovSmirnov / Shapiro-Wilk Test). The Mann-Whitney U Test was used as a statistical method for statistical significance between two independent groups, and the Kruskal Wallis Test between three independent groups, for variables that were found to be inconsistent with the normal distribution. When a significant difference was detected between three independent groups, Bonferroni correction was applied in post-hoc paired comparisons to determine the source of the difference. Statistical significance level was accepted as $p<0.05$.

\section{Results}

Within the scope of the research, a total of 200 patients with a diagnosis of COPD, 100 of whom were from the 2rd hospital and 100 from the 3rd hospital patients, were examined.

The median age of the second level patients was 69 (IQR: 67 78), and the numbers of men and women were equal. 9.0\% of the patients were still smoking, $7.0 \%$ cessation of smoking and the remaining $84.0 \%$ had never smoked. $78.0 \%$ of the second level patients diagnosed with COPD had at least one additional disease. In these diseases; hypertension took the first place with $41.0 \%$, followed by diabetes mellitus with $32.0 \%$ and heart failure and asthma with $14.0 \%$. The least common additional diseases were hyperlipidemia (20\%), chronic renal failure (4.0\%) and bronchitis (7.0\%) (Table 1).

When looking at the 3 rd level patients examined within the scope of the research; while the median age was 56 (IQR: 53-58), the numbers of men and women were equal. $66.0 \%$ of the patients were smoking, while the remaining $34.0 \%$ were not. $47.0 \%$ of the patients with COPD had additional disease. Among the existing additional diseases, hypertension took the first place with $18.0 \%$, diabetes mellitus with $14.0 \%$ and heart failure with $10.0 \%$. The least common additional diseases were bronchitis (1.0\%), chronic renal failure (3.0\%) and hyperlipidemia (4.0\%) (Table 1).

The median number of outpatient clinic apply in the last two years was 11 (IQR: 5.2-17.0), while the median number of hospitalizations in the last two years was 2 (IQR: 1-3) in the 2rd level patients with COPD. The patients were hospitalized for a median of 6 (IQR: $4-9$ ) days. $25.0 \%$ of the 2 rd patients diagnosed with COPD had stayed in the intensive care unit (ICU). The median length of stay in the ICU was 3 (IQR: 1.0-10.5) days. The median length of hospital stay in all patients with COPD was 7 (IQR: 5-11) days. 


\begin{tabular}{|c|c|c|}
\hline & $2^{\text {nd }}$ level $(n=100)$ & $3^{\text {rd }}$ level $(n=100)$ \\
\hline Age (year), median (IQR) & $69(61-78)$ & $56(53-58)$ \\
\hline \multicolumn{3}{|l|}{ Sex, n (\%) } \\
\hline Male & $50(50.0 \%)$ & $50(50.0 \%)$ \\
\hline Female & $50(50.0 \%)$ & $50(50.0 \%)$ \\
\hline \multicolumn{3}{|l|}{ Smoking status, n (\%) } \\
\hline Still using & $9(9.0 \%)$ & $66(66.0 \%)$ \\
\hline Stopped smoking & $7(7.0 \%)$ & $0(0 \%)$ \\
\hline Never used & $84(84.0 \%)$ & $34(34.0 \%)$ \\
\hline Presence of additional diseases, $\mathbf{n}(\%)$ & $78(78.0 \%)$ & $47(47.0 \%)$ \\
\hline \multicolumn{3}{|l|}{ Existing diseases, $\mathbf{n}(\%)$} \\
\hline HT & $41(41.0 \%)$ & $18(18.0 \%)$ \\
\hline DM & $32(32.0 \%)$ & $14(14.0 \%)$ \\
\hline $\mathrm{HF}$ & $14(14.0 \%)$ & $10(10.0 \%)$ \\
\hline Asthma & $14(14.0 \%)$ & $8(8.0 \%)$ \\
\hline Bronchitist & $7(7.0 \%)$ & $1(1.0 \%)$ \\
\hline $\mathrm{CHR}$ & $4(4.0 \%)$ & $3(3.0 \%)$ \\
\hline HL & $2(2.0 \%)$ & $4(4.0 \%)$ \\
\hline Other & $16(16.0 \%)$ & $29(29 . \% 0)$ \\
\hline
\end{tabular}

The median number of outpatient clinic apply of patients with 3rd level COPD in the last two years was 5 (IQR: 2-9), while the median number of hospitalizations in the last two years was 1 (IQR: 0-2). The median length of stay in the service was 7 (IQR: 5-10) days. $29.0 \%$ of the patients with a diagnosis of 3rd level COPD that were remained in the ICU. The average length of stay in the ICU was 3 (IQR: 2-7) days. The median length of hospital stay in all patients with level 3 COPD was 8 (IQR: 5.0-11.8) days.

Hospital costs of the patients examined within the scope of the study were calculated as USD. According to this; the median cost of the ICU of 25 of the patients with 2rd level COPD who stayed in the ICU was 448.6 (IQR: 181.5-1416.7) USD. While the median hospital cost of the $2 \mathrm{rd}$ level patients hospitalized in the ICU was USD 701.7 (IQR: 306.9-1526.2), the median hospital cost of the patients not hospitalized in the ICU was USD 274.7 (IQR: 196.1490.2). The median total cost of the hospital for the $2 \mathrm{rd}$ level patients was 305.0 (IQR: 216.2-593.5) USD (Figure 1a,b,c and d).

The median ICU cost of 29 of the patients with a diagnosis of 3rd level COPD who stayed in the ICU was 602.7 (IQR: 383.2-1073.4) USD. The median hospital cost of the 3rd level patients staying in the ICU was 1780.3 (IQR: 1057-9-2201.0) USD, while the median hospital cost of the 3rd level patients not staying in the ICU was 318.0 (IQR: 191.1-469.7) USD. The median total cost of the hospital for 3rd level patients was 424.9 (IQR: 257.8-1000.0) USD (Figure 1a,b,c and d).

While antibiotic treatment was applied to $50.0 \%$ of the 2 rd level patients examined within the scope of the study, it was applied to $71.0 \%$ of the 3 rd level patients. The median duration of antibiotic use was 6.5 (IQR: 4-10) days for 2rd level patients, while it was 6.0 (IQR: 4-10) days for 3rd level patients. Looking at the antibiotics used; while cefuroxime was applied to $36.0 \%$ of the 2rd level patients and ceftriaxone was applied to $14.0 \%$ of the 2 rd patients, the ceftriaxone was applied in the first place with $40.0 \%$ of 3 rd patient, followed by moxifloxacin with $23.0 \%$ of $3 \mathrm{rd}$ patient and cefuroxime with $16.0 \%$ of 3 rd patient (Table 2).

The median total antibiotic cost of 50 patients who received antibiotic treatment among the 2rd level patients was 17.9 (IQR: 11.5-25.8) USD, while the median total antibiotic cost of 71 patients who received antibiotic treatment among the 3rd level patients was 65.4 (IQR: 34.5-155.5) USD ( Table 3).

Among patients who applied to 2 rd level health care institutions and hospitalized in ICU, total hospital cost was significantly higher than those who did not $(p<0.001)$. In addition, as the length of hospitalization increased, the total cost of the hospital increased significantly ( $p<0.001)$ (Table 4). On the other hand, no statistically significant differences were found between the 

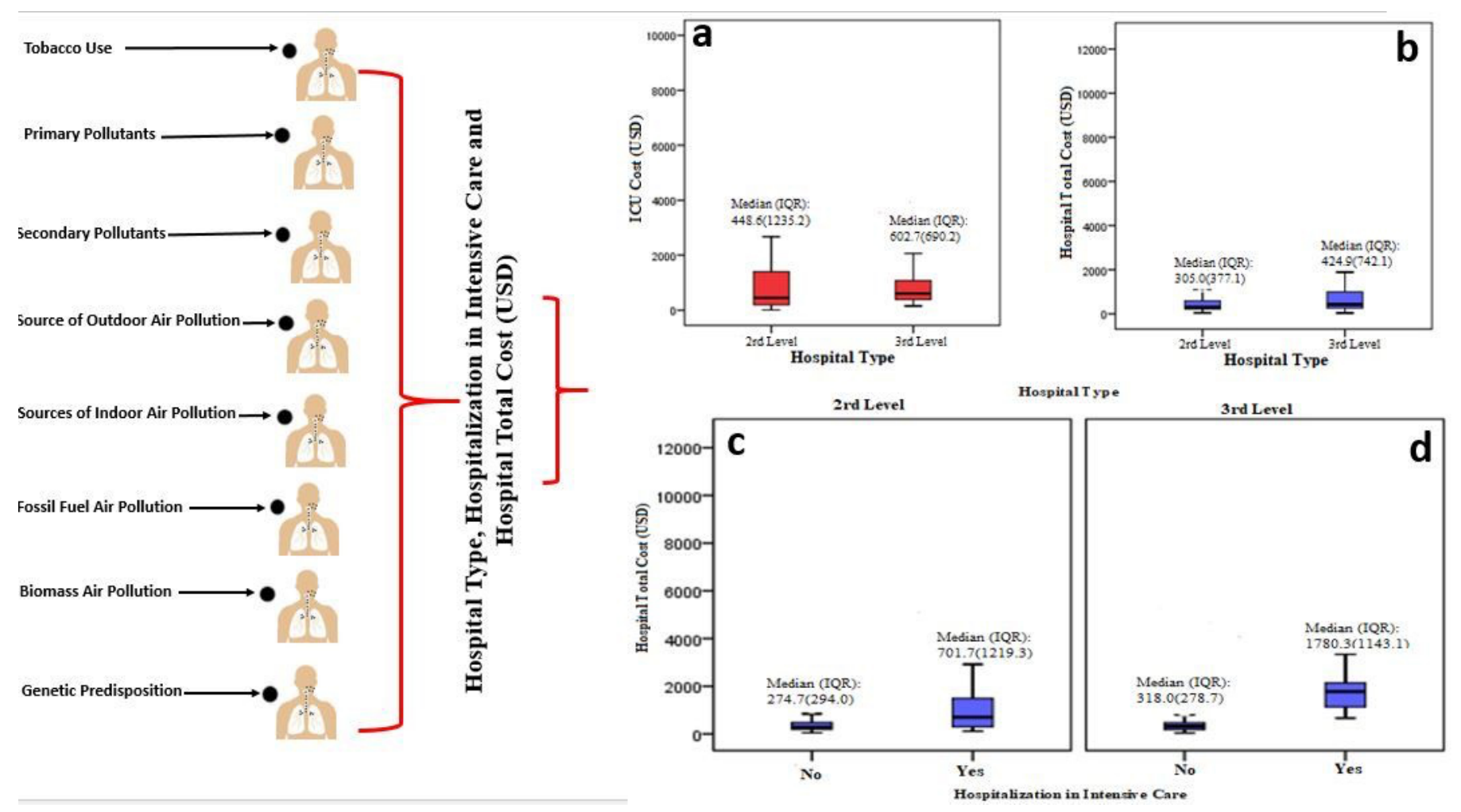

Figure 1. Risk factors for COPD (Tobacco use, source of outdoor air pollution, primary and secondary pollutants, fossil fuel air pollution, sources of indoor air pollution, biomass air pollution, genetic predisposition). Patients are divided into three groups as follows. Distribution of total hospital cost and ICU cost according to the health institution level applied by COPD patients (a, b) and distribution of the total cost of the hospital according to the hospitalization status in the ICU at the health institution levels applied by the patients with COPD (c, d)

COPD: Chronic obstructive lung disease, ICU: Intensive care unit

age groups, gender, smoking status, comorbidities, antibiotic use, number of outpatient clinic admissions, and the number of hospitalizations in the last two years in terms of total hospital cost ( $p>0.05)(p>0.05)$ (Table 4). Looking at patients with tertiary COPD diagnosis; hospital total cost was significantly higher among men than women, those who were hospitalized in the ICU than non- hospitalized in the ICU, those who did use antibiotics than who did not use antibiotics, and those with more than 10 outpatient apply from less than 5 , and those between 5-10 ( $p=$ $0.025 ; p<0.001 ; p<0.001 ; p<0.001)$. Also when the number of admissions and length of hospital stay increased in the last two years, the total cost of the hospital increased significantly ( $p$ $<0.001$ for both) (Table 4).

On the other hand, no statistically significant difference was found between the age groups, smoking status and comorbidities of the patients with COPD who applied to the 3rd level hospital in terms of the total cost of the hospital ( $p>0.05$ ) (Table 4).

Distribution of age, comorbidity, smoking status, antibiotic use, and length of stay at the healthcare institution level of patients with COPD according to sex and smoking status were given in the table 5 and 6.

\section{Discussion}

According to the GOLD 2017 report; COPD is a common, preventable and treatable disease characterized by persistent airflow restriction and respiratory symptoms due to airway and I or alveolar abnormalities, usually caused by severe exposure to harmful particles or gas. COPD is one of the most important causes of illness, death and disability worldwide (1).

COPD is a very common and heterogeneous disease with increasing morbidity and mortality worldwide, placing a significant burden on healthcare providers. Although pharmacological and nonpharmacological treatment options are abundant, smoking cessation continues to be the most effective therapeutic and preventive intervention in the care of these patients (4).

Since patients with COPD are mostly smokers or have used smokers, additional diseases such as cardiovascular system, circulatory system and central system diseases may be developed 


\begin{tabular}{|c|c|c|}
\hline & $2^{\text {nd }}$ level $(n=100)$ & $3^{\text {rd }}$ level $(n=100)$ \\
\hline \multicolumn{3}{|l|}{ Antibiotic use status, n (\%) } \\
\hline No & $50(50.0 \%)$ & $29(29.0 \%)$ \\
\hline Yes & $50(50.0 \%)$ & $71(71.0 \%)$ \\
\hline Antibiotic use time (day), median (IQR) & $6.5(4-10)$ & $6.0(4-10)$ \\
\hline \multicolumn{3}{|l|}{ Antibiotics used, n (\%) } \\
\hline Ceftriaxone & $14(14.0 \%)$ & $40(40.0 \%)$ \\
\hline Cefuroxime & $36(36.0 \%)$ & $16(16.0 \%)$ \\
\hline Moxifloxacin & $0(0 \%)$ & $23(23.0 \%)$ \\
\hline Piperacillin & $0(0 \%)$ & $8(8.0 \%)$ \\
\hline Ampicillin & $0(0 \%)$ & $6(6.0 \%)$ \\
\hline Ciprofloxacin & $0(0 \%)$ & $6(6.0 \%)$ \\
\hline Meropenem & $0(0 \%)$ & $6(6.0 \%)$ \\
\hline Clarithromycin & $0(0 \%)$ & $6(6.0 \%)$ \\
\hline Cefazolin & $0(0 \%)$ & $4(4.0 \%)$ \\
\hline Imipenem & $0(0 \%)$ & $4(4.0 \%)$ \\
\hline Levofloxacin & $0(0 \%)$ & $3(3.0 \%)$ \\
\hline Teicoplanin & $0(0 \%)$ & $3(3.0 \%)$ \\
\hline Vancomycin & $0(0 \%)$ & $3(3.0 \%)$ \\
\hline Tigecycline & $0(0 \%)$ & $2(2.0 \%)$ \\
\hline Fusidic acid & $0(0 \%)$ & $2(2.0 \%)$ \\
\hline Amoxicillin & $0(0 \%)$ & $1(1.0 \%)$ \\
\hline Colistin & $0(0 \%)$ & $1(1.0 \%)$ \\
\hline Linezolid & $0(0 \%)$ & $1(1.0 \%)$ \\
\hline Caspofungin & $0(0 \%)$ & $1(1.0 \%)$ \\
\hline Rifamycin & $0(0 \%)$ & $1(1.0 \%)$ \\
\hline Metronidazole & $0(0 \%)$ & $1(1.0 \%)$ \\
\hline
\end{tabular}

Table 3. Distribution of total costs of antibiotics used by patients with COPD according to the level of healthcare institution

\begin{tabular}{|c|c|c|}
\hline & $2^{\text {nd }}$ level $(n=50)$ & $3^{\text {rd }}$ level $(n=71)$ \\
\hline & Median (IQR) & Median (IQR) \\
\hline Total antibiotic cost (USD) & $17.9(11.5-25.8)$ & $65.4(34.5-155.5)$ \\
\hline
\end{tabular}

because of smoking. In addition to the primary effects of COPD on the lung in these patients, these systemic effects and accompanying diseases also require treatment and increase the cost of the disease (8).

In our study, when the additional diseases to be considered in both 2rd and 3rd level patients, hypertension took the first place, followed by diabetes mellitus, heart failure and asthma. The least common additional diseases were hyperlipidemia, chronic renal failure and bronchitis.
It was reported that women with COPD were younger and their number of pack years was considerably lower than it was among men. Also in COPD patiens, men had increased risk for comorbidities or tended to be and greatly higher among mortality men than women (9). Interestingly, it was reported that. COPD is still mainly a "men's disease" (10). Also, while COPD mortality is especially decreasing among men, similar pronounced change has not been observed among women, and it may be said that COPD mortality in women will surpass or is surpassing that in men $(11,12)$. 
Table 4. Distribution of total hospital costs according to some descriptive and clinical characteristics at the health institution levels where COPD patients apply

\begin{tabular}{|c|c|c|c|c|}
\hline \multirow{5}{*}{ Age group } & \multicolumn{4}{|c|}{ Hospital total cost (USD) } \\
\hline & \multicolumn{2}{|c|}{$2^{\text {nd }}$ level } & \multicolumn{2}{|c|}{$3^{\text {rd }}$ level } \\
\hline & \multirow[t]{2}{*}{ n } & \multirow[t]{2}{*}{ Median (IQR) } & \multirow[t]{2}{*}{$\mathbf{n}$} & \multirow[t]{2}{*}{ Median (IQR) } \\
\hline & & & & \\
\hline & 11 & $271.8(181.8-514.3)$ & 33 & $499.5(253.3-893.4)$ \\
\hline 55-65 yaş & 33 & $376.2(212.5-627.7)$ & 67 & $366.6(257.3-1141.2)$ \\
\hline$>65$ yaş & 56 & $291.5(227.8-593.5)$ & 0 & ------ \\
\hline$p$-value & & $0.572^{\mathrm{a}}$ & & $0.608^{b}$ \\
\hline \multicolumn{5}{|l|}{ Sex } \\
\hline Male & 50 & $292.8(205.9-526.0)$ & 50 & 718.9 (291.5-1780.3) \\
\hline Female & 50 & $343.7(222.0-701.7)$ & 50 & 347.4 (233.0-643.8) \\
\hline$p$-value & & $0.176^{\mathrm{b}}$ & & $0.025^{b}$ \\
\hline \multicolumn{5}{|l|}{ Smoking } \\
\hline Yes & 16 & $365.3(232.2-790.0)$ & 66 & $450.1(233.0-1175.4)$ \\
\hline No & 84 & $305.0(209.0-582.8)$ & 34 & 359.4 (279.1-835.9) \\
\hline p-value & & $0.625^{\mathrm{b}}$ & & $0.558^{b}$ \\
\hline \multicolumn{5}{|c|}{ Additional diseases } \\
\hline Yes & 78 & 302.1 (207.0-596.9) & 47 & $366.6(259.4-1278.0)$ \\
\hline No & 22 & 333.7 (228.5-482.4) & 53 & $457.4(245.8-991.5)$ \\
\hline$p$-value & & $0.897^{\mathrm{b}}$ & & $0.814^{\mathrm{b}}$ \\
\hline \multicolumn{5}{|l|}{ ICU admission } \\
\hline Yes & 25 & 701.7 (306.9-1526.2) & 29 & $1780.3(1057.9-2201.0)$ \\
\hline No & 75 & 274.7 (196.1-490.2) & 71 & 318.0 (191.1-469.7) \\
\hline$p$-value & & $<0.001^{b}$ & & $<0.001^{b}$ \\
\hline \multicolumn{5}{|l|}{ Antibiotic use } \\
\hline Yes & 50 & $319.1(210.6-600.0)$ & 71 & 638.3 (341.6-1499.5) \\
\hline No & 50 & $291.5(216.5-584.8)$ & 29 & $235.0(147.4-347.4)$ \\
\hline$p$-value & & $0.615^{\mathrm{b}}$ & & $<0.001^{\mathrm{b}}$ \\
\hline \multicolumn{5}{|c|}{ Outpatient clinic applications number } \\
\hline$<5$ & 18 & $418.9(233.4-843.9)$ & 41 & $280.8(173.6-616.1)$ \\
\hline Between 5-10 & 31 & $294.0(216.2-452.9)$ & 38 & $463.6(300.7-852.8)$ \\
\hline$>10$ & 51 & $291.5(204.9-600.2)$ & 21 & $1789.5(772.6-2426.0)^{x y}$ \\
\hline p-value & & $0.154^{\mathrm{a}}$ & & $<0.001^{\mathrm{a}}$ \\
\hline \multicolumn{5}{|c|}{ Hospitalizations number in the last 2 years } \\
\hline Never & 7 & $600.2(312.6-1935.2)$ & 49 & $280.8(185.7-388.9)^{y z}$ \\
\hline $1-2$ & 56 & $295.0(198.3-641.8)$ & 27 & $538.8(304.0-974.5)^{z}$ \\
\hline$\geq 3$ & 37 & $285.2(211.9-548.1)$ & 24 & $1707.5(875.9-2080.7)$ \\
\hline$p$-value & & $0.163^{\mathrm{a}}$ & & $<0.001^{\mathrm{a}}$ \\
\hline \multicolumn{5}{|c|}{ Length of stay in the hospital } \\
\hline$\leq 5$ day & 29 & $183.7(131.6-271.7)^{y z}$ & 27 & $180.6(119.7-235.0)^{y z}$ \\
\hline 6-10 day & 44 & $291.5(247.1-417.2)^{z}$ & 44 & $388.9(307.5-768.5)^{z}$ \\
\hline$\geq 11$ day & 27 & 627.7 (549.2-1593.3) & 29 & $1780.3(718.9-2201.0)$ \\
\hline$p$-value & & $<0.001^{\mathrm{a}}$ & & $<0.001^{\mathrm{a}}$ \\
\hline
\end{tabular}


Table 5. Distribution of age, comorbidity, smoking status, antibiotic use, and length of stay at the healthcare institution level where COPD patients apply according to sex

\begin{tabular}{|c|c|c|c|c|c|c|}
\hline & \multicolumn{3}{|c|}{$2^{\text {nd }}$ level } & \multicolumn{3}{|c|}{$3^{\text {rd }}$ level } \\
\hline & \multicolumn{2}{|c|}{ Sex } & \multirow[t]{2}{*}{ p-value } & \multicolumn{2}{|l|}{ Sex } & \multirow[t]{2}{*}{ p-value } \\
\hline & $\begin{array}{l}\text { Male } \\
(n=50)\end{array}$ & $\begin{array}{l}\text { Female } \\
(n=50)\end{array}$ & & $\begin{array}{l}\text { Male } \\
(n=50)\end{array}$ & Female $(n=50)$ & \\
\hline Age (year), median (IQR) & $70.5(61-78)$ & $69(59.8-80.0)$ & 0.975 & $56(53.8-58.0)$ & $56(53-58)$ & 0.972 \\
\hline Additional diseases, $\mathbf{n}(\%)$ & $36(72.0)$ & $42(84.0)$ & 0.148 & $17(34.0)$ & $30(60.0)$ & 0.009 \\
\hline Hospitalization (days), median (IQR) & $7.5(4.8-10.2)$ & $7(5-13)$ & 0.570 & $8(6.0-16.2)$ & $7(5-10)$ & 0.064 \\
\hline Use of Antibiotics, $n$ (\%) & $21(42.0)$ & $29(58.0)$ & 0.110 & $40(80.0)$ & $31(62.0)$ & 0.047 \\
\hline
\end{tabular}

Table 6. Distribution of age, presence of comorbidities, antibiotic use and length of stay at the healthcare institution level where COPD patients apply according to smoking status

\begin{tabular}{|c|c|c|c|c|c|c|}
\hline & \multicolumn{3}{|c|}{$2^{\text {nd }}$ level } & \multicolumn{3}{|c|}{$3^{\text {rd }}$ level } \\
\hline & \multicolumn{2}{|c|}{ Smoking } & \multirow[t]{2}{*}{ p-value } & \multicolumn{2}{|c|}{ Smoking } & \multirow[t]{2}{*}{ p-value } \\
\hline & $\begin{array}{l}\text { Yes } \\
(n=16)\end{array}$ & $\begin{array}{l}\text { No } \\
(n=84)\end{array}$ & & $\begin{array}{l}\text { Yes } \\
(n=66)\end{array}$ & $\begin{array}{l}\text { No } \\
(n=34)\end{array}$ & \\
\hline Age (year), median (IQR) & $63.5(55.5-75.0)$ & $70.5(61.0-79.8)$ & 0.165 & $56(53-58)$ & $57(53-58)$ & 0.615 \\
\hline Additional Diseases, n (\%) & $9(56.3)$ & $69(82.1)$ & $0.043^{c}$ & $31(47.0)$ & $16(52.9)$ & 0.993 \\
\hline Smoking, $\mathrm{n}(\%)$ & $7.5(5.2-9.0)$ & $7(5-11)$ & 0.883 & $8(5.0-12.2)$ & $7(4.8-11.2)$ & 0.574 \\
\hline Hospitalization (days), median (IQR) & $5(31.3)$ & $45(53.6)$ & 0.102 & $51(77.3)$ & $20(58.8)$ & 0.054 \\
\hline
\end{tabular}

According to our results, the man had higher smoking status than women. In the 3rd level patients with COPD; hospital total cost was significantly higher among men than women, those who were hospitalized in the ICU than non- hospitalized in the ICU, those who did use antibiotics than who did not use antibiotics, and those with more than 10 outpatient apply from less than 5, and those between 5-10, respectively. In addition, as the number of admissions and length of hospital stay increased in the last two years, the total cost of the hospital increased significantly, too.

COPD is a major public health problem and will remain a challenge for clinicians within the 21st century. COPD puts enormous pressure on healthcare systems due to its high prevalence, morbidity and mortality. The prevalence of COPD in the population has significant effects in daily life compared to other chronic conditions, and serious resources are required. Therefore it is important to allocate minimum resources and reduce the relative impact of COPD (13).

According to our results, the median total antibiotic cost of 50 patients who received antibiotic treatment among the 2 rd level patients studied was 17.9 USD, while the median total antibiotic cost of 71 patients who received antibiotic treatment among the 3rd level patients was 65.4 USD. Accordingly, the cost of the 3rd level patients using antibiotics was higher than the 2nd level patients. We think that this is due to the fact that the prognosis of patients admitted to 3rd hospitals is more severe compared to 2rd hospitals.

According to hospital costs of the patients, the median cost of the ICU of the patients with 2 rd level COPD who stayed in the ICU was 448.6 USD. While the median hospital cost of the $2 \mathrm{rd}$ level patients hospitalized in the ICU was 701.7 USD, the median hospital cost of the patients not hospitalized in the ICU was 274.7 USD. The median total cost of the hospital for the 2 rd level patients was 305.0 USD. Also, the median ICU cost of 29 of the patients with COPD who stayed in the ICU of 3rd level hospital was 602.7 USD. The median hospital cost of the 3 rd level patients staying in the ICU was 1780.3 USD, while the median hospital cost of the 3rd level patients not staying in the ICU was 318.0 (IQR: 191.1-469.7) USD. The median total cost of the hospital for 3rd level patients was 424.9 USD. Among patients who hospitalized in ICU, total hospital cost was significantly higher than those who did not. In addition, as the length of hospitalization increased, 
the total cost of the hospital increased significantly. It can be said that when the number and duration of patients hospitalized in the ICU increased, the total cost of the hospital increased, too.

\section{Conclusion}

COPD is an extremely common heterogeneous disease all over the world. This disease affects people at different levels, causing serious costs over the state from hospitals and also loss of workforce. The frequency of hospital admissions, the length of stay in the intensive care unit, the bad prognosis of the disease and the drugs used cause serious financial burdens and loss of healthcare personnel time. There are pharmacological and non-pharmacological treatment options for the disease. For this reason, the elimination and prevention of the both of internal and external factors that cause the disease, especially without the need for medication, is of great importance in terms of both financial and labor loss prevention and reduction.

\section{Ethics}

Ethics Committee Approval: This study was approved by University of Health Sciences, Konya Training and Research Hospital (decision no and date: 16-03, 05/07/2018).

Informed Consent: Retrospective study.

Peer-review: Externally peer-reviewed.

\section{Authorship Contributions}

Surgical and/or Medical Practices: K.Y., Ö.A., Concept: K.Y., Ö.A., Design: K.Y., Ö.A., Data Collection and/or Processing: K.Y., Ö.A., Analysis and/or Interpretation: Ö.A., Literature Search: K.Y., Writing: K.Y.

Conflict of Interest: No conflict of interest was declared by the authors.

Financial Disclosure: The authors declared that this study received no financial support.

\section{References}

1. GOLD 2017. Global Strategy for the Diagnosis, Management and Prevention of COPD. Available at: http://goldcopd.org/gold-2017-global-strategydiagnosismanagement- prevention-copd/. Accessed September 5, 2018. https://doi.org/10.1016/j.mcna.2018.12.005.

2. National Center for Health Statistics (US). Health, United States, 2015: With Special Feature on Racial and Ethnic Health Disparities. Hyattsville (MD): National Center for Health Statistics (US); 2016 May. Report No.: 2016-1232.

3. Lozano R, Naghavi M, Foreman K, Lim S, Shibuya K, Aboyans V, et al. Global and regional mortality from 235 causes of death for 20 age groups in 1990 and 2010: a systematic analysis for the Global Burden of Disease Study 2010 Lancet. 2012:380:2095-128.

4. Duffy SP, Criner GJ. Chronic Obstructive Pulmonary Disease: Evaluation and Management. Med Clin North Am. 2019;103:453-61.

5. Eisner MD, Anthonisen N, Coultas D, Kuenzli N, Perez-Padilla R, Postma D, et al. An official American Thoracic Society public policy statement: Novel risk factors and the global burden of chronic obstructive pulmonary disease. Am J Respir Crit Care Med. 2010;182:693-718.

6. Mut S, Ağırbaş I. Hastanelerde Maliyet Analizi: Ankara'da Hizmet Sunan Íkinci Basamak Bir Kamu Hastanesi'nde Uygulama. Mehmet Akif Ersoy Üniversitesi Sosyal Bilimler Enstitüsü Dergisi. 2017;9:202-17.

7. Adeloye D, Chua S, Lee C, Basquill C, Papana A, Theodoratou E, et al. Global and regional estimates of COPD prevalence: Systematic review and metaanalysis. J Glob Health. 2015;5:020415

8. T.C. Sağlık Bakanlığı Temel Sağlık Hizmetleri Genel Müdürlüğü. Türkiye kronik hava yolu hastalıklarını (astım - koah) önleme ve kontrol programı (2009 - 2013 Ankara. ISBN: 978-975-590-287-6.

9. Backman BH, Virchow JC, Lundbäck B. COPD in women - New results presented. Respir Med. 2021;176:106238.

10. Perez TA, Castillo EG, Ancochea J, Pastor Sanz MT, Almagro P, MartínezCamblor P, et al. Sex differences between women and men with COPD: A new analysis of the 3CIA study. Respir Med. 2020;171:106105.

11. Ni H, Xu J. COPD-related Mortality by Sex and Race Among Adults Aged 25 and Over: United States, 2000-2014. NCHS Data Brief. 2016;(256):1-8.

12. Lortet-Tieulent J, Soerjomataram I, López-Campos JL, Ancochea J, Coebergh JW, Soriano JB. International trends in COPD mortality, 1995-2017. Eur Respir J. 2019;54:1901791.

13. López-Campos JL, Tan W, Soriano JB. Global burden of COPD. Respirology. 2016;21:14-23 